\title{
Myocardial infarction in patients over 90 years of age
}

\author{
This article was published in the following Dove Press journal: \\ Clinical Interventions in Aging \\ 28 February 2012 \\ Number of times this article has been viewed
}

\section{Josef Yayan}

Department of Internal Medicine, Vinzentius-Hospital, Cornichonstraße 4, Landau, Germany
Correspondence: Josef Yayan

Department of Internal Medicine,

Vinzentius-Hospital, Cornichonstraße 4,

D-76829 Landau, Germany

$\mathrm{Tel}+49634 \mid 176128$

Fax +49 634I 142254

Email josef.yayan@hotmail.com
Background: The aim of this study was to examine the trend in increasing life expectancy in relation to heart attack and cardiac catheterization.

Methods: A retrospective study of very elderly patients over 90 years of age (study group) and between 70 and 79 years of age (control group) with myocardial infarction and acute coronary syndrome who underwent coronary angiography was conducted.

Results: A total of 1100 cardiac catheterizations were performed in the cardiac catheterization laboratory of Vinzentius-Hospital in Landau, Germany from 2007 to 2011. The number of coronary angiographies performed in patients aged over 90 years and those aged 70-79 years was 36 and 354, respectively, during this same time period. No increase in the number of evidence-based therapy for coronary heart disease by cardiac catheterization was observed in the very elderly patients over this time period.

Conclusion: An increase in the number of patients aged over 90 years and a rise in heart attacks, as evaluated by coronary angiography, could not be found in this study.

Keywords: myocardial infarction, elderly patients, angiography, evidence-based therapy

\section{Introduction}

An increase in life expectancy has been reported in developed countries and the result will be an aging population. ${ }^{1}$ A consequence of this development is an increase in heart attacks in older people.

Despite the extensive published information regarding the treatment of acute coronary syndrome (ACS), there are few data available for the guidance and evaluation of ACS management in the elderly, since only a minority of published clinical trials include elderly patients. ${ }^{2}$ Even when elderly patients are enrolled in clinical trials, they typically account for a disproportionately small portion of the study population, and age-subset-specific results are often not reported. ${ }^{3,4}$ Indeed, patients older than 75 years of age comprise only $9 \%$ of clinical trial populations, and only about $50 \%$ of trials enroll patients above the age of 75 years. ${ }^{5}$ Data guiding coronary reperfusion in elderly ACS patients are limited and consist mostly of subset analyses from major trials and retrospective studies. ${ }^{6}$

According to guidelines, patients with non-ST-elevation myocardial infarction (NSTEMI) and acute ST-segment elevation myocardial infarction (STEMI) on the electrocardiogram should undergo a primary percutaneous coronary intervention.? Although no age limit for this treatment is specified in the guidelines, older patients with myocardial infarction are less often treated with invasive treatment. ${ }^{8}$ The most common cause of death in developed countries is ischemic heart disease in patients 
over 65 years of age. ${ }^{9}$ This is most evident in Europe, where the aging of the population has led to an increase in coronary heart disease. ${ }^{10}$ This current trend is expected to continue with the increase in life expectancy. ${ }^{10}$ This study investigates the trend of increasing life expectancy in relation to myocardial infarction and left heart catheterization.

\section{Methods}

\section{Study groups}

This study was retrospective, and examined patients aged 90-100 years (study group) with angina pectoris, NSTEMI, and acute STEMI on an electrocardiogram. These patients were compared with patients between 70 and 79 years of age who had the same symptoms and diagnoses (control group) from 2007 to 2011. In total, 1100 patients were evaluated during this time period. All patients in this study underwent coronary angiography. The cardiovascular risk factors examined were elevated blood pressure, diabetes mellitus, hyperlipidemia, obesity, smoking, and a family history of cardiovascular disease. Comorbidities and the length of hospital stay of patients admitted to hospital were also compared between the two groups. All patients with myocardial infarction were treated with a loading dose of aspirin (500 mg), clopidogrel (300 mg), and a single dose of heparin (5000 IU), followed by a typical daily dose of aspirin and clopidogrel. A major adverse cardiac event was defined as death, history of stroke, or myocardial infarction.

\section{Statistical analysis}

The confidence interval of a proportion was calculated given the necessary size of this study and results. The KolmogorovSmirnov test was used to compare the length of the hospital stay. The survival rate for both groups was calculated using the Kaplan-Maier method and comparison of gender distribution among groups was calculated using the KruskalWallis test. Data were checked afterwards for normality using the Kolmogorov-Smirnov test. A $P$ value of $<0.05$ was considered statistically significant. Mean and standard deviation (SD) were also calculated.

\section{Results}

\section{Primary percutaneous coronary intervention}

A total of 1100 left heart catheterizations were performed in this Vinzentius-Hospital in Landau, Germany from 2007 to 2011. Only $36(3.27 \%)$ patients over 90 years of age were treated by cardiac catheterization from 2007 to 2011, whereas 354 (32.18\%) patients aged 70-79 years underwent coronary angiography in the same time period. In 2007, 39 coronary angiographies were carried out, with four $(10.26 \%)$ and six $(15.38 \%)$ of them performed in the study and control groups, respectively. In 2008, the number of invasive examinations significantly increased to 231 . Eight $(3.46 \%)$ and $81(35.06 \%)$ patients in the study and control groups, respectively, underwent coronary angiography. In $2009,15(4.63 \%)$ patients in the study group and $111(34.26 \%)$ in the control group from a total of 324 invasive treatments underwent coronary angiography. A slight decline in numbers of coronary angiographies to a total of 283 was observed in 2010 , thus, seven $(2.47 \%)$ patients in the study group and 89 $(31.45 \%)$ in the control group were examined. Finally, the number of invasive investigations decreased to 223 in 2011 (Figure 1). This decrease was observed in both groups. Two $(0.90 \%)$ patients in the study group and $67(30.04 \%)$ in the control group were treated by coronary angiography.

\section{Age and gender distribution}

The mean age of the study and control groups was $91.5(\mathrm{SD} \pm 1.8)$ and $74.6(\mathrm{SD} \pm 2.8)$ years, respectively. The oldest patient was a 97 -year-old man. Among the 36 patients in the study group, 14 (38.89\%) men and 22 (61.11\%) women underwent cardiac catheterization, whereas 211 (59.60\%) men and 143 (40.40\%) women underwent the procedure in the control group (Figure 2). According to the Kruskal-Wallis test, significantly more women than men underwent cardiac catheterization in the study group, whereas more men than women underwent the procedure in the control group.

\section{Clinical appearance}

Most cases of 235 (60.26\%) were ACS. Nine (3.83\%) were in the study group, whereas $226(96.17 \%)$ were in the control group. Meanwhile, 134 (34.36\%) patients had NSTEMI, with $25(18.66 \%)$ patients and $109(81.34 \%)$ in the study and control

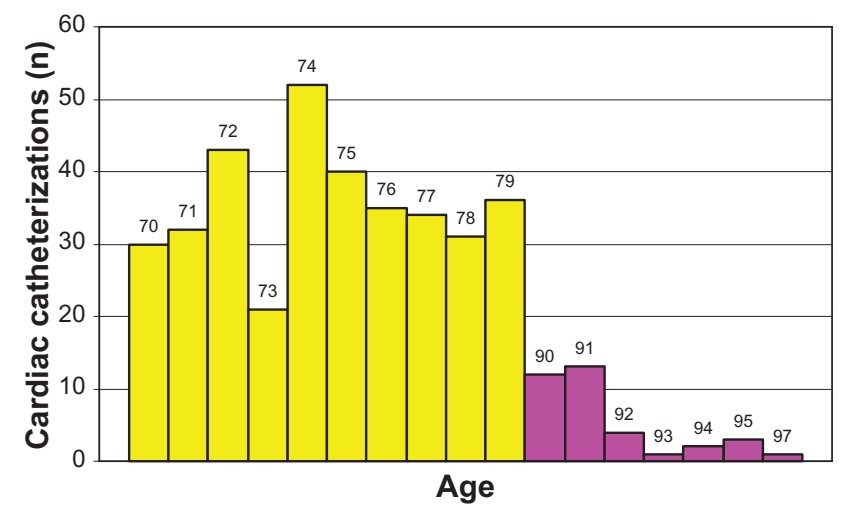

Figure I The number of cardiac catheterizations in the two groups: 70 to 79 years of age and 90 to 97 years of age in 2007-2011. 


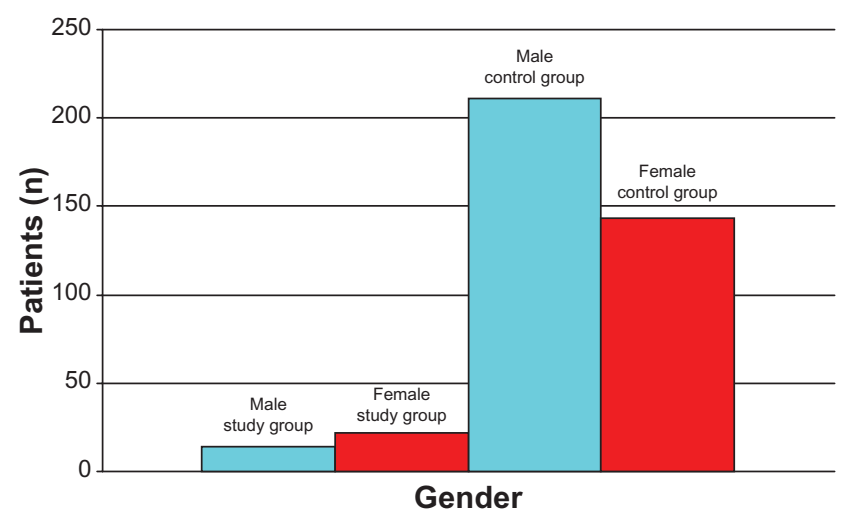

Figure 2 The gender distribution of the two groups.

groups, respectively. At least 21 (5.38\%) patients had STEMI: two $(9.52 \%)$ in the study group and $19(90.48 \%)$ in the control group. In the control group, coronary angiography was performed because of abnormal ergometry in four patients.

\section{Cardiovascular risk factors}

Among the 36 patients in the study group, 30 (83.33\%) had hypertension, $18(50 \%)$ diabetes, six (16.67\%) hyperlipidemia, and four $(11.11 \%)$ were obese. One patient smoked. Among the 354 patients in the control group, $296(83.62 \%)$ had hypertension, 194 (54.80\%) diabetes, 159 (44.92\%) hyperlipidemia, 64 (18.08\%) were obese, 54 (15.25\%) had a nicotine habit, and 17 $(4.8 \%)$ had a positive family history for cardiovascular disease.

\section{Coronary heart disease}

A total of 271 (69.49\%) patients in both groups had coronary heart disease. Of these, 30 (11.07\%) and 241 (88.93\%) were in the study and control groups, respectively. In contrast, only $95(24.36 \%)$ patients had no coronary artery disease. Five $(5.26 \%)$ of these patients were in the study group, while $90(94.74 \%)$ were in the control group. Nineteen $(4.87 \%)$ patients in the control group and five $(1.28 \%)$ in the study group had coronary atherosclerosis.

\section{Length of hospital stay}

The average length of the hospital stay was 12.6 (SD \pm 8.154 ) days in the study group and $8(\mathrm{SD} \pm 5.669)$ days in the control group. The Kolmogorov-Smirnov test showed that the normal distribution in the study and control groups was 4.566 and 33.762 , respectively, with a significant deviation of at least $99 \%$ from a normal distribution.

\section{Comorbidities}

The accompanying diseases in the study group involved heart and circulatory (51 diagnoses), kidney (22), thyroid (9), lung (4), gastrointestinal (4), and electrolyte disturbances (2). Meanwhile, the comorbidities in the control group were heart and circulatory (298 diagnoses), kidney (99), gastrointestinal (47), lung (37), thyroid (31), electrolyte disturbances (29), infections (17), and neurological disorders (7) (Figure 3).

\section{Major adverse cardiac event}

In the study group, one patient had a history of stroke compared with 47 patients in the control group. Among the 36 patients in the study group, no deaths occurred, so the probability of survival using the Kaplan-Meier method was $100 \%$ (95\% confidence interval [CI]: 100\%-100\%). In the control group, $3 / 351$ died, giving a probability of survival of 99.15\% (95\% CI: 98.19\%-100\%).

\section{Discussion}

An increase in the number of coronary angiographies was observed in both groups; however, a continuous increase was not detected in this present study. From 2007 to 2011, $\sim 10 \%$ of the angiographies in this study were performed in patients aged 90 years or older relative to the control group.

\section{A}

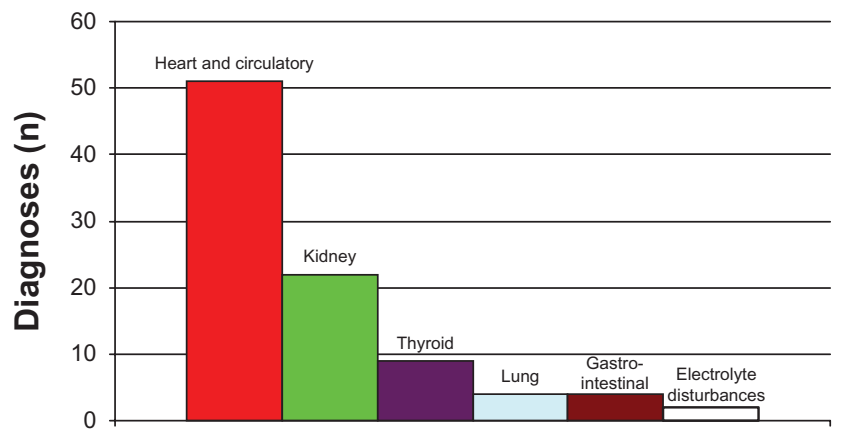

B

Comorbidities in the study group

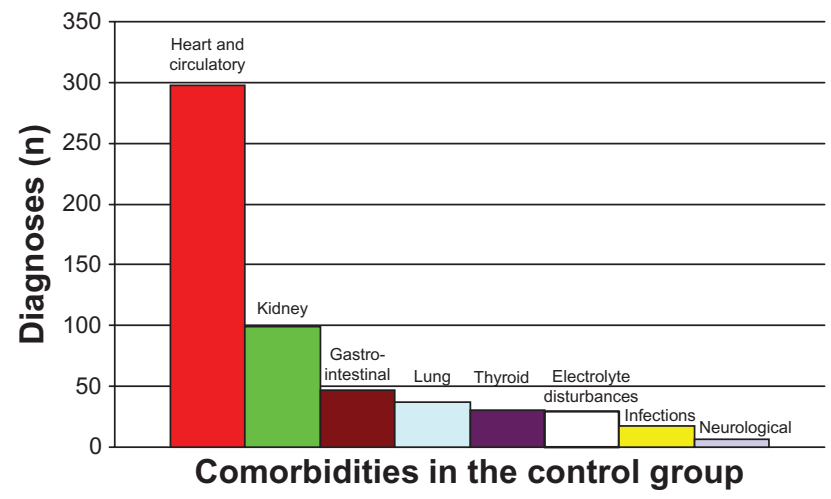

Figure 3 The various comorbidities in the two groups over the last few years. (A) Study group; (B) Control group. 
NSTEMI occurred most frequently in the study group, whereas ACS was more common in the control group. Elderly ACS patients are more likely to have comorbid conditions such as diabetes mellitus, renal insufficiency, cerebrovascular disease, and heart failure. ${ }^{11,12}$ Moreover, limited functional capacity and dementia are also more common within this group of patients, so that these factors must be taken into account in management decisions. ${ }^{11,12}$ Further, in a previous study by Tespili et al, elderly patients, who were primarily female, had more comorbidities and more extensive cardiovascular disease prior to stroke. ${ }^{13}$ In this current study, however, the cardiovascular risk factors differed only slightly between the two groups, but older patients in the study group had more comorbidities (Figure 3), while stroke and death was more common in the control group. The probability of survival was markably better in the study group. Finally, the study group had a higher proportion of women than men.

According to recent studies, invasive therapy significantly improves the survival of elderly patients with acute myocardial infarction. ${ }^{14}$ In this current study, the probability of survival was notably better among older elderly patients than younger ones. Patients with advanced age, pre-existing coronary artery disease, prior stroke, pre-existing renal failure, obesity, NSTEMI, prior ACS, and presence of supraventricular arrhythmias were found to be significantly more likely to undergo conservative treatment. ${ }^{15}$ In-hospital mortality was significantly higher in conservatively treated patients. ${ }^{13}$ This trend of conservative treatment in elderly with myocardial infarction appears to continue, according to this study.

Elderly patients represent a substantial proportion of the population admitted to hospital with myocardial infarction, and receive less evidenced-based therapy. ${ }^{16}$ Further, age is an independent predictor of short- and medium-term mortality. ${ }^{16}$ In addition, a significant decrease in the utilization rate of invasive diagnostic coronary angiography and increased inhospital mortality were observed as patient age increased. ${ }^{17}$ Approximately $33 \%$ of all ACS episodes occur in patients over 75 years old and account for approximately $60 \%$ of overall mortality due to ACS. ${ }^{18-20}$ The incidence of ACS in the elderly is projected to increase due to advances in prior ACS treatment in an aging population..$^{21,22}$

\section{Conclusion}

This study did not observe an increase in evidence-based therapy for coronary heart disease by cardiac catheterization in very elderly patients over recent years.

\section{Disclosure}

The author reports no conflicts of interest in this work.

\section{References}

1. Andrawes WF, Bussy C, Belmin J. Prevention of cardiovascular events in elderly people. Drugs Aging. 2005;22:859-876.

2. Jokhadar M, Wenger NK. Review of the treatment of acute coronary syndrome in elderly patients. Clin Interv Aging. 2009;4:435-444.

3. Thygesen K, Alpert JS, White HD. Joint ESC/ACCF/AHA/WHF Task Force for the Redefinition of Myocardial Infarction. Universal definition of myocardial infarction. Eur Heart J. 2007;28:2525-2538.

4. DeWood MA, Spores J, Notske R, et al. Prevalence of total coronary occlusion during the early hours of transmural myocardial infarction. N Engl J Med. 1980;303:897-902.

5. DeWood MA, Spores J, Hensley GR, et al. Coronary arteriographic findings in acute transmural myocardial infarction. Circulation. 1983;68: I39-I49.

6. Liebson PR, Klein LW. The non-Q wave myocardial infarction revisited: 10 years later. Prog Cardiovasc Dis. 1997;39:399-444.

7. Hunyadi-Anticević S, Colak Z, Funtak IL, et al. European Resuscitation Council guidelines for resuscitation 2010. Lijec Vjesn. 2011; 133:1-14.

8. Rymuza H, Kowalik I, Drzewiecki A, et al. Successful primary coronary angioplasty improves early and long-term outcomes in ST segment elevation acute coronary syndromes in patients above 80 years of age. Kardiol Pol. 2011;69:346-354.

9. Kesteloot H, Sans S, Kromhout D. Dynamics of cardiovascular and all-cause mortality in Western and Eastern Europe between 1970 and 2000. Eur Heart J. 2006;27:107-113.

10. Escaned J, Rydén L, Zamorano JL, et al. Trends and contexts in European cardiology practice for the next 15 years: the Madrid Declaration: a report from the European Conference on the Future of Cardiology, Madrid, June 2-3, 2006. Eur Heart J. 2007;28: 634-637.

11. Alexander KP, Newby LK, Cannon CP, et al. Acute coronary care in the elderly, part I: Non-ST-segment-elevation acute coronary syndromes: a scientific statement for healthcare professionals from the American Heart Association Council on Clinical Cardiology: in collaboration with the Society of Geriatric Cardiology. Circulation. 2007;115: 2549-2569.

12. Alexander KP, Newby LK, Cannon CP, et al. Acute coronary care in the elderly, part II: ST-segment-elevation myocardial infarction: a scientific statement for healthcare professionals from the American Heart Association Council on Clinical Cardiology: in collaboration with the Society of Geriatric Cardiology. Circulation. 2007;115: 2570-2589.

13. Tespili M, Guagliumi G, Valsecchi O, et al. In-hospital clinical outcome in elderly patients with acute myocardial infarction treated with primary angioplasty. Ital Heart J. 2003;4:193-198.

14. Polewczyk A, Janion M, Gasior M, Gierlotka M, Poloński L. Benefits from revascularisation therapy in the elderly with acute myocardial infarction. Comparative analysis of patients hospitalised in 1992-1996 and in 2005-2006. Kardiol Pol. 2010;68:873-881.

15. Rittger H, Schnupp S, Sinha AM, et al. Predictors of treatment in acute coronary syndromes in the elderly: Impact on decision making and clinical outcome after interventional vs conservative treatment. Catheter Cardiovasc Interv. 2011. Epub Nov 25.

16. Timóteo AT, Ramos R, Toste A, et al. [Impact of age on treatment and outcomes after acute myocardial infarction, particularly in very elderly patients.] Rev Port Cardiol. 2011. Epub Nov 21. Portuguese.

17. Hsieh TH, Wang JD, Tsai LM. Improving in-hospital mortality in elderly patients after acute coronary syndrome-A nationwide analysis of 97,220 patients in Taiwan during 2004-2008. Int J Cardiol. 2011. Epub Nov 5. 
18. Alexander KP, Roe MT, Chen AY, et al. Evolution in cardiovascular care for elderly patients with non-ST-segment elevation acute coronary syndromes: Results from the CRUSADE National Quality Improvement Initiative. J Am Coll Cardiol. 2005;46:1479-1487.

19. Goldberg RJ, McCormick D, Gurwitz JH, et al. Age-related trends in short- and long-term survival after acute myocardial infarction: a 20-year population-based perspective (1975-1995). Am J Cardiol. 1998;82(11):1311-1317.
20. Roger VL, Jacobsen SJ, Weston SA, et al. Trends in the incidence and survival of patients with hospitalized myocardial infarction, Olmsted County, Minnesota, 1979 to 1994. Ann Intern Med. 2002;136(5): 341-348.

21. Mackay J, Mensah G. The Atlas of Heart Disease and Stroke. Geneva: World Health Organization; 2004.

22. Center for Disease Control. Public health and aging: Trends in aging: United States and worldwide. MMWR. 2003;52:101-106.

\section{Publish your work in this journal}

Clinical Interventions in Aging is an international, peer-reviewed journal focusing on evidence-based reports on the value or lack thereof of treatments intended to prevent or delay the onset of maladaptive correlates of aging in human beings. This journal is indexed on PubMed Central, MedLine, the American Chemical Society's 'Chemical Abstracts Ser-

\section{Dovepress}

vice' (CAS), Scopus and the Elsevier Bibliographic databases. The manuscript management system is completely online and includes a very quick and fair peer-review system, which is all easy to use. Visit $\mathrm{http}: / /$ www.dovepress.com/testimonials.php to read real quotes from published authors.

Submit your manuscript here: http://www.dovepress.com/clinical-interventions-in-aging-journal 